\title{
Morphotype markers of virulence in human candidal infections
}

\author{
P. R. HUNTER, CHERRY A. M. FRASER and D. W. R. MACKENZIE*
}

Division of Hospital Infection and *Mycological Reference Laboratory, Central Public Health Laboratory, 61 Colindale Avenue, London NW9 5 HT

\begin{abstract}
Summary. A study of the morphotypes of 446 strains of Candida albicans, isolated from a variety of clinical specimens, is reported. The method was based on a morphotyping scheme that has recently been described, but not all of the potential characters were used in this analysis. By this limited code, 50 different morphotypes were distinguished, the largest group comprising $23 \%$ of the population. The simplicity and good discrimination of the method make it a useful typing scheme for C. albicans. Discontinuous colonial fringes were associated with strains from oral sites and deep infections. Significantly, $67 \%$ of strains from fatal infections were of the discontinuous fringe type, compared to only $11 \%$ of strains from other infections. Further associations between morphotype and anatomical source included narrow-coarse fringes in genitourinary isolates.
\end{abstract}

\section{Introduction}

Several typing schemes have been developed in recent years for the sub-species differentiation of Candida albicans. These include biotyping (Odds and Abbott, 1980), resistotyping (McCreight and Warnock, 1982), sensitivity to "killer yeasts" (Polonelli et al., 1983), extracellular enzyme production (Roman and Sicilia, 1983), immunoblotting (Lee et al., 1986) and DNA fingerprinting (Scherer and Stevens, 1987). So far none of these methods has been shown to differentiate between strains of high and low virulence.

A new typing scheme for $C$. albicans, which is based on colonial morphology (morphotyping), has recently been described (Phongpaichit et al., 1987). We undertook this study of a collection of clinical isolates to determine the variety and distribution of morphotypes of $C$. albicans and also to determine whether the method is able to detect strains of proven virulence.

\section{Materials and methods}

\section{Candida strains}

The 446 strains were received directly from laboratories following a request in the Communicable Disease Report in addition to those referred to the Mycological Reference Laboratory, Colindale, London. Strains that had been

Received 11 Feb. 1988; accepted 20 May 1988. submitted as part of another study were excluded from analysis so as not to bias the population of strains in favour of those laboratories taking part in such studies. Multiple isolates from the same patient were also excluded for similar reasons. The strains examined were grouped according to site of isolation as genitourinary and faecal (184 isolates), skin and wound (69), oral cavity and respiratory tract (118), and deep sites including blood culture, CSF and biopsy specimens (75). A further eight strains were excluded from the study because they could not be easily classified into one of the above groups. The geographical location of the laboratories submitting strains and the clinical source of those strains are shown in table $\mathrm{I}$.

\section{Morphotyping}

Isolates were sub-cultured on to blood-agar plates and incubated overnight at $37^{\circ} \mathrm{C}$, to ensure absence of bacterial contamination. Identification was by germ-tube formation in serum. One colony, chosen at random, was further sub-cultured on to Bacto YM Agar (0712-01-8 Difco, Detroit, MI, USA), from which a suspension in distilled water was made for inoculation on to morphotyping agar as described by Phongpaichit et al., (1987).

After incubation for 10 days, each strain was examined and assigned a morphotype code (Phongpaichit et al., 1987) of two pairs of three numbers, with an occasional additional number being added in parenthesis. To simplify analysis, a limited code was used in this study. Fringe characters were recorded in full, but only the topography of streak surface features was analysed. The abbreviated code is shown in table II and examples of 
Table I. Geographical sources of strains isolated from various sites

\begin{tabular}{|c|c|c|c|c|c|}
\hline \multirow[b]{2}{*}{ Source } & \multicolumn{5}{|c|}{ Number of strains isolated from } \\
\hline & $\begin{array}{c}\text { Genitourinary } \\
\text { tract } \\
{[n=184]}\end{array}$ & $\begin{array}{c}\text { Skin } \\
{[n=69]}\end{array}$ & $\begin{array}{l}\text { Oral cavity } \\
{[\mathrm{n}=118]}\end{array}$ & $\begin{array}{c}\text { Deep } \\
{[n=75]}\end{array}$ & $\begin{array}{c}\text { Total } \\
{[n=446]}\end{array}$ \\
\hline $\begin{array}{l}\text { London and S.E. England } \\
\qquad(\mathrm{i}=27)\end{array}$ & 63 & 39 & 47 & 58 & 207 \\
\hline $\begin{array}{l}\text { S.W. England } \\
(\mathrm{i}=1)\end{array}$ & 1 & 0 & 1 & 0 & 2 \\
\hline $\begin{array}{l}\text { Midlands } \\
(i=6)\end{array}$ & 13 & 1 & 2 & 6 & 22 \\
\hline $\begin{array}{l}\text { N.W. England } \\
(i=7)\end{array}$ & 42 & 5 & 23 & 5 & 75 \\
\hline $\begin{array}{l}\text { N.E. England } \\
(\mathrm{i}=4)\end{array}$ & 55 & 3 & 13 & 1 & 72 \\
\hline $\begin{array}{l}\text { Wales } \\
(i=2)\end{array}$ & 9 & 21 & 31 & 2 & 63 \\
\hline $\begin{array}{l}\text { Overseas } \\
\quad(i=3)\end{array}$ & 1 & 0 & 1 & 3 & 5 \\
\hline
\end{tabular}

$\mathrm{i}=$ number of referring institutions in each region.

Table II. Coding of morphological features

\begin{tabular}{|c|c|c|}
\hline Feature & Code & Description \\
\hline \multicolumn{3}{|l|}{ Fringe } \\
\hline \multirow{6}{*}{ Distribution } & 0 & Absent \\
\hline & 1 & Discontinuous; $<20 \%$ of margin \\
\hline & 2 & Discontinuous; $20-50 \%$ of margin \\
\hline & 3 & Discontinuous $; 60-90 \%$ of margin \\
\hline & 5 & $\begin{array}{l}\text { Continuous at periphery only or } \\
\text { strands conspicuously fan shaped }\end{array}$ \\
\hline & 7 & $\begin{array}{l}\text { Continuous; filamentous outgrowths } \\
\text { parallel }\end{array}$ \\
\hline \multirow[t]{4}{*}{ Width } & 0 & Absent \\
\hline & 2 & $\leqslant 2 \mathrm{~mm}$ \\
\hline & 3 & $3-5 \mathrm{~mm}$ \\
\hline & 5 & $\geqslant 6 \mathrm{~mm}$ \\
\hline \multirow[t]{5}{*}{ Texture } & 0 & Absent \\
\hline & 1 & Very coarse \\
\hline & 2 & Coarse \\
\hline & 3 & Intermediate \\
\hline & 4 & Fine \\
\hline \multicolumn{3}{|l|}{ Streak surface } \\
\hline \multirow[t]{7}{*}{ Topography } & 0 & Smooth \\
\hline & 1 & Nodular \\
\hline & 2 & Pitted \\
\hline & 4 & Crateriform \\
\hline & 5 & Crateriform plus wrinkles or folds \\
\hline & 6 & Wrinkles or folds \\
\hline & 8 & Hairy \\
\hline
\end{tabular}

strain morphotypes are shown in the figure. For statistical analysis, the morphotype code was reduced to just six fringe states and two surface states, as shown in table IV. Those coded 000 were classed as no fringe, those with initial digit $1,2,3$, or 5 as discontinuous fringes, $753 / 4$ as wide-fine fringes, $751 / 2$ as wide-coarse, $723 / 4$ and $733 / 4$ as narrow-fine and $721 / 2$ and $731 / 2$ as narrow coarse. For surface features, those with a smooth surface were classed as featureless and all others as featured.

\section{Results}

The distribution of morphotypes amongst strains isolated from various sites is shown in table III. With the abbreviated code of this study, 50 different morphotypes were identified. The commonest morphotype codes were $0000(23 \%), 7540(16 \%)$ and $7340(7 \%)$.

To determine whether morphotypes varied between geographical regions within the United Kingdom, strains from the South of England and the Midlands were compared with strains from Wales and the North of England (table IV). As strains from deep infections were predominantly from the South, they were not included in the analysis of geographical variation. There was no significant difference in the clinical source of strains between the two regions, although there was a difference in the distribution of fringe characteristics $\left(\chi^{2}=18 \cdot 1,5 \mathrm{df}, \mathrm{p}<0 \cdot 01\right)$. This was mainly due to a predominance of strains with narrow-fine fringes in the South of England. It is of particular note that there was no difference in the proportion of strains with discontinuous fringes between the two regions.

There was a significant difference in the distri- 

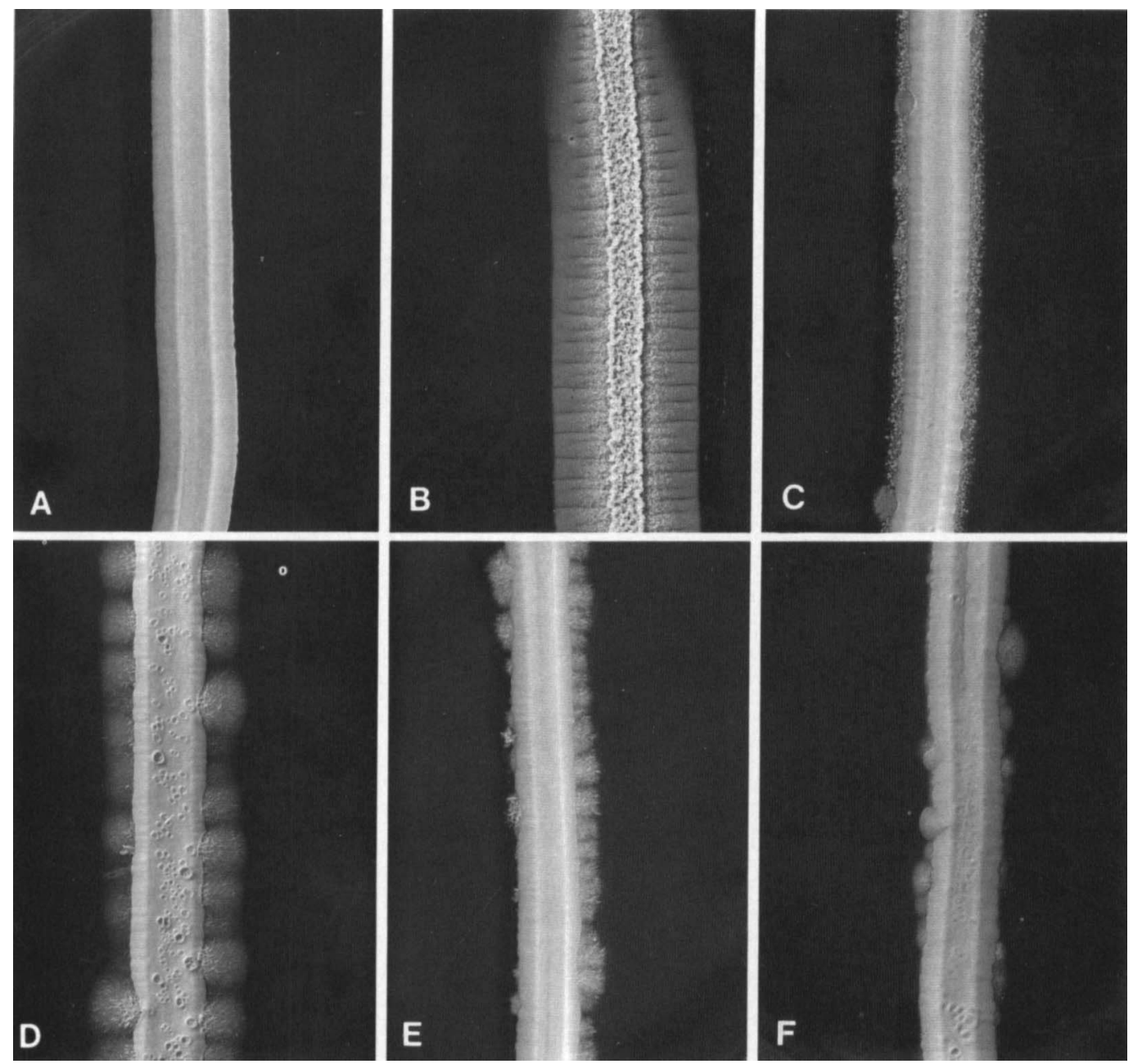

Figure. Some examples of $C$. albicans morphotypes, coded with short code used in this study: $(A)=0000 ;(B)=7546 ;(C)=7220$; $(D)=5344 ;(E)=3320 ;(F)=1230$.

bution of fringe characteristics between the three categories of superficial infection $\left(\chi^{2}=41 \cdot 7,10 \mathrm{df}\right.$, $\mathrm{p}<0.001)$ as shown in table $\mathrm{V}$. The main differences were the preponderance of discontinuous fringes among oral isolates and of narrow-coarse fringes among genitourinary + faecal isolates. There was a significant difference between strains from superficial and those from deep infections $\left(\chi^{2}=29 \cdot 0,5 \mathrm{df}\right.$ $\mathrm{p}<0.01$ ). This was mainly due to the frequency of discontinuous fringes in deep infections, although deep infections were also less likely to show widefine fringes. Furthermore, in those strains from known fatal infections, $67 \%$ were of the discontinuous fringe type compared to only $11 \%$ from other deep infections ( $p=0.0001$, Fisher's exact test), and none was of the wide-fine fringe type. Therefore, a deep infection caused by a discontinuous fringed strain was associated with a significantly increased risk of death when compared with a deep infection caused by another fringe pattern. This association of discontinuous fringe type with deep infections held even when strains from the South East were analysed alone $(\mathrm{p}=0.0004)$, and was not due to any particular outbreak as all but two were from separate institutions. There were no significant differences found for surface features.

\section{Discussion}

There must be some concern about the reproducibility of a typing scheme based on colonial morphology, as this is a feature reported to undergo phenotypic variation (Slutsky et al., 1985). Indeed, 
Table III. Distribution of morphotypes of $C$. albicans between strains isolated from various sites

\begin{tabular}{|c|c|c|c|c|c|c|}
\hline \multirow{2}{*}{\multicolumn{2}{|c|}{$\begin{array}{l}\text { Morphotype } \\
\text { code }\end{array}$}} & \multicolumn{5}{|c|}{ Number of strains isolated from } \\
\hline & & \multirow{2}{*}{$\begin{array}{c}\begin{array}{c}\text { Genitourinary } \\
\text { tract } \\
{[n=184]}\end{array} \\
45\end{array}$} & \multirow{2}{*}{$\begin{array}{c}\begin{array}{c}\text { Skin } \\
{[\mathrm{n}=69]}\end{array} \\
18\end{array}$} & \multirow{2}{*}{$\frac{\begin{array}{c}\text { Oral cavity } \\
{[n=118]}\end{array}}{20}$} & \multirow{2}{*}{$\frac{\begin{array}{c}\text { Deep } \\
{[\mathrm{n}=75]}\end{array}}{19}$} & \multirow{2}{*}{$\frac{\begin{array}{c}\text { Total } \\
{[\mathrm{n}=446]}\end{array}}{102}$} \\
\hline & 0 & & & & & \\
\hline & 4 & 0 & 0 & 1 & 0 & 1 \\
\hline 000 & 6 & 3 & 0 & 0 & 0 & 3 \\
\hline 123 & 0 & 0 & 0 & 1 & 0 & 1 \\
\hline & 0 & 0 & 0 & 0 & 1 & 1 \\
\hline 223 & 6 & 1 & 0 & 2 & 0 & 3 \\
\hline & 0 & 0 & 0 & 0 & 1 & 1 \\
\hline 323 & 0 & 1 & 0 & 0 & 3 & 4 \\
\hline & 0 & 0 & 0 & 0 & 2 & 2 \\
\hline 331 & 4 & 0 & 0 & 0 & 1 & 1 \\
\hline 332 & 0 & 0 & 0 & 3 & 6 & 9 \\
\hline 532 & 0 & 0 & 1 & 1 & 1 & 3 \\
\hline 532 & 5 & 0 & 1 & 0 & 0 & 1 \\
\hline & 0 & 0 & 0 & 2 & 0 & 2 \\
\hline 534 & 0 & 0 & 0 & 1 & 0 & 1 \\
\hline 551 & 0 & 0 & 0 & 3 & 0 & 3 \\
\hline 721 & 0 & 4 & 2 & 1 & 2 & 9 \\
\hline 722 & 0 & 9 & 1 & 6 & 2 & 18 \\
\hline 722 & 4 & 1 & 0 & 0 & 1 & 2 \\
\hline 722 & 6 & 0 & 0 & 1 & 0 & 1 \\
\hline 723 & 0 & 1 & 0 & 0 & 1 & 2 \\
\hline 723 & 6 & 1 & 0 & 0 & 0 & 1 \\
\hline 724 & 0 & 6 & 1 & 3 & 3 & 13 \\
\hline 724 & 4 & 0 & 0 & 1 & 1 & 2 \\
\hline 724 & 6 & 2 & 1 & 1 & 0 & 4 \\
\hline 731 & 0 & 2 & 1 & 0 & 3 & 6 \\
\hline 732 & 0 & 20 & 0 & 2 & 2 & 24 \\
\hline 732 & 2 & 0 & 0 & 0 & 2 & 2 \\
\hline 732 & 4 & 1 & 0 & 0 & 0 & 1 \\
\hline 732 & 5 & 1 & 0 & 0 & 1 & 2 \\
\hline 732 & 6 & 5 & 1 & 0 & 2 & 8 \\
\hline 733 & 0 & 5 & 2 & 5 & 3 & 15 \\
\hline 733 & 4 & 0 & 1 & 0 & 0 & 1 \\
\hline 733 & 5 & 3 & 1 & 1 & 0 & 5 \\
\hline 733 & 6 & 5 & 0 & 2 & 2 & 9 \\
\hline 734 & 0 & 8 & 6 & 13 & 4 & 31 \\
\hline & 4 & 3 & 5 & 0 & 0 & 8 \\
\hline 734 & 5 & 0 & 0 & 1 & 0 & 1 \\
\hline 734 & 6 & 1 & 2 & 3 & 0 & 6 \\
\hline 752 & 0 & 8 & 0 & 7 & 3 & 18 \\
\hline 752 & 2 & 3 & 0 & 0 & 0 & 3 \\
\hline 752 & 6 & 0 & 0 & 1 & 0 & 1 \\
\hline 753 & 0 & 3 & 5 & 3 & 1 & 12 \\
\hline 753 & 5 & 1 & 0 & 0 & 0 & 1 \\
\hline 754 & 0 & 33 & 11 & 21 & 7 & 72 \\
\hline 754 & 1 & 0 & 0 & 1 & 0 & 1 \\
\hline 754 & 2 & 0 & 1 & 0 & 0 & 1 \\
\hline 754 & 4 & 0 & 2 & 0 & 1 & 3 \\
\hline 754 & 5 & 1 & 2 & 2 & 0 & 5 \\
\hline 754 & 6 & 7 & 4 & 9 & 0 & 20 \\
\hline
\end{tabular}


Table IV. Distribution of morphotypes between two regions

\begin{tabular}{l|cc}
\hline & \multicolumn{2}{|c}{ Number $(\%)$ of isolates from } \\
\cline { 2 - 3 } $\begin{array}{l}\text { Morphotypic } \\
\text { characters }\end{array}$ & $\begin{array}{c}\text { South England } \\
\text { and Midlands } \\
{[\mathrm{n}=167]}\end{array}$ & $\begin{array}{c}\text { North England } \\
\text { and Wales } \\
{[\mathrm{n}=202]}\end{array}$ \\
\hline $\begin{array}{l}\text { Fringe characters } \\
\text { No fringe }\end{array}$ & $40(24)$ & $46(23)$ \\
$\begin{array}{l}\text { Discontinuous } \\
\text { Complete } \\
\quad \text { wide-fine } \\
\text { wide-coarse } \\
\text { narrow-fine } \\
\text { narrow-coarse }\end{array}$ & $6(4)$ & $11(5)$ \\
$\begin{array}{l}\text { Streak surface } \\
\text { featureless }\end{array}$ & $40(24)$ & $66(33)$ \\
featured & $11(7)$ & $8(4)$ \\
& $18(11)$ & $39(19)$ \\
\hline
\end{tabular}

Brown-Thomsen (1968) found poor reproducibility with his typing scheme, which was also based on colonial morphology, as he noted a shift from smooth to rough colonial forms. However, phenotypic switching mainly affects the colony surface. Brown-Thomsen (1968) based his typing scheme mainly on these potentially unstable surface features. It is not yet known if phenotypic switching will affect morphotyping results, particularly as the morphotyping streak is seeded by many thousand colony forming units. The in-vitro reproducibility over 2 years for this morphotyping scheme, relying mainly on fringe features, is $84 \%$ for those giving an identical morphotype, and $96 \%$ for those giving a morphotype differing by one or less adjacent characters (Phongpaichit et al., 1987). In a further study (Hunter and Fraser, unpublished data) of 15 cases of candidal vaginitis, in which five colonies from each of the original cultures were morphotyped, we found that there was $100 \%$ in-vivo reproducibility.

The discrimination of this method, using the reduced code, is very good compared with some other methods developed for $C$. albicans. In this

Table V. Distribution of morphotypic characters of $C$. albicans between strains isolated from various sites

\begin{tabular}{|c|c|c|c|c|c|}
\hline \multirow[b]{3}{*}{ Character } & \multicolumn{5}{|c|}{ Number $(\%)$ of isolates from } \\
\hline & \multicolumn{3}{|c|}{ Superficial infections } & \multicolumn{2}{|c|}{ Deep infections } \\
\hline & $\begin{array}{c}\text { Genitourinary } \\
\text { tract } \\
{[n=184]}\end{array}$ & $\begin{array}{c}\text { Skin } \\
{[n=69]}\end{array}$ & $\begin{array}{l}\text { Oral cavity } \\
{[\mathrm{n}=118]}\end{array}$ & $\begin{array}{c}\text { Fatal } \\
{[n=12]}\end{array}$ & $\begin{array}{c}\text { Non-fatal } \\
{[n=63]}\end{array}$ \\
\hline \multicolumn{6}{|l|}{ Fringe characters } \\
\hline No fringe & $48(26)$ & $18(26)$ & $21(18)$ & $2(17)$ & $17(27)$ \\
\hline Discontinuous & $2(1)$ & $2(3)$ & $13(11)$ & $8(67)$ & $7(11)$ \\
\hline Complete & & & & & \\
\hline wide-fine & $45(24)$ & $25(36)$ & $36(30)$ & 0 & $9(14)$ \\
\hline wide-coarse & $11(6)$ & 0 & $8(7)$ & 0 & $3(5)$ \\
\hline narrow-fine & $35(19)$ & $19(28)$ & $30(25)$ & $1(8)$ & $13(21)$ \\
\hline narrow-coarse & $43(23)$ & $5(7)$ & $10(9)$ & $1(8)$ & $15(24)$ \\
\hline \multicolumn{6}{|l|}{ Streak surface } \\
\hline Featureless & $145(79)$ & $48(70)$ & $92(88)$ & $10(83)$ & $54(86)$ \\
\hline Featured & $39(21)$ & $21(30)$ & $26(22)$ & $2(17)$ & $9(14)$ \\
\hline
\end{tabular}

$0=\% ; n=$ number of isolates. 
study, 50 different morphotypes were described, the largest group accounting for only $23 \%$ of all strains. The corresponding figures obtained with other methods are : 10 types for DNA fingerprinting with the most frequent type representing $35 \%$ of strains (Scherer and Stevens, 1987); 16 types and $54 \%$ for immunoblotting (Lee et al., 1986); four types and $64 \%$ for enzyme biotyping (Roman and Sicilia, 1983).

The combination of simplicity with good discrimination make morphotyping an ideal typing method for first-line use. Strains of the same morphotype from epidemiologically related cases can be assumed to be related, until proven otherwise.

Another potential use of any typing scheme is as an indicator of virulence. Whilst some bacterial typing schemes do identify strains of increased virulence (Turk, 1982; Jann and Jann, 1985) this has not been found to be the case for current typing schemes for C. albicans (Odds et al., 1983a, b; Hunter and Fraser, 1987). It has been suggested that smooth fringeless colonies (000 0 or Al by Brown-Thomsen's method) are the wild type (Brown-Thomsen, 1968) and so could be the most virulent. If this is the case then one should expect to see increased numbers of this morphotype in strains isolated from blood cultures. No such association was observed in this study. It has been shown previously that overheating of the media during preparation abolishes fringe formation (Phongpaichit et al., 1987), which may explain the large number of Al strains previously reported.

Perhaps the most striking finding in this study was the strong association between morphotyping and anatomical source of the isolate. This was particularly marked for the association between discontinuous fringe formation and fatal deep infections. The mechanism for this association is unknown at present, though we have formulated three possible explanations. Firstly, it may be that some surface phenomenon is responsible for both virulence and morphotype. Indeed, those bacterial typing schemes most closely associated with virulence, type on the basis of surface structures (Turk, 1982; Jann and Jann, 1985). The most comprehensively studied virulence factor for $C$. albicans is adherence to epithelial cells (Barrett-Bee et al., 1985; Ghannoum and Elteen, 1986; Bibel et al.,

\section{REFERENCES}

Barrett-Bee K, Hayes Y, Wilson R G, Ryley J F 1985 A comparison of phospholipase activity, cellular adherence and pathogenicity of yeasts. Journal of General Microbiology 131 : $1217-1221$.
1987). Adherence of $C$. albicans has been shown to be due to molecules present on the cell surface (Ghannoum et al., 1986; Critchley and Douglas, 1987). Whether these molecules have any effect on morphotype is also unknown, though the effect of surface structures on bacterial colonial morphology and virulence is well known (Munoz and Bergman, 1977; Sereny, 1977; Morse and Brooks, 1985). Another possibility is that it is related to anti-fungal therapy; however, as several of the strains we examined were sampled from patients before the start of chemotherapy, this can be excluded. A third possibility could be related to phenotypic switching which has been described in vaginal isolates (Soll et al., 1987). C. albicans can exist in either a mycelial or a yeast form, and presumably discontinuous fringe formation occurs because only a small proportion of the cells on the streak margin are growing in the mycelial form. Full virulence may depend on the cell being in different growth forms at different stages of the infection. Clearly, a population of invading cells which are switching between the two forms are likely to be more virulent than cells committed to one or other form.

The other associations of morphotype with anatomical source are also difficult to explain. The increased number of discontinuous fringed strains from oral sites may reflect the variety of the ecological environment within the oral cavity. The variety of niches may favour those strains that can readily adapt from one niche to another. Whether there is any direct relationship between oral strains and strains from deep infections is unclear. Narrowcoarse fringe formation in genitourinary isolates may indicate that these strains adhere more firmly to the epithelial cells lining the genitourinary tract.

Whatever the mechanism of the association between virulence and fringe formation, morphotyping may offer a useful in-vitro indicator of virulence for $C$. albicans. This has obvious value in assessing the clinical significance and prognostic implications of blood-culture isolates of C. albicans. Furthermore, detailed study of the mechanism of this phenomenon may well enable the development of more rapid methods for detection of such virulent strains and may also lead to novel therapeutic approaches based on the inhibition of such growth forms.

Bibel D J, Aly R, Lahti L, Shinefield H R, Maibach H I 1987 Microbial adherence to vulvar epithelial cells. Journal of Medical Microbiology 23: 75-82.

Brown-Thomsen J 1968 Variability in Candida albicans (Robin) Berkhout. I. Studies in morphology and biological activity. Hereditas 60: 355-398. 
Critchley I A, Douglas L J 1987 Isolation and partial characterization of an adhesin from Candida albicans. Journal of General Microbiology 133: 629-636.

Ghannoum M A, Burns G R, Abu Elteen K, Radwan S S 1986 Experimental evidence for the role of lipids in adherence of Candida spp. to human buccal epithelial cells. Infection and Immunity 54: 189-193.

Ghannoum M, Abu Elteen K 1986 Correlative relationship between proteinase production, adherence and pathogenicity of various strains of Candida albicans. Journal of Medical and Veterinary Mycology $24: 407-413$.

Hunter P R, Fraser C 1987 The use of modified resistogram to type Candida albicans isolated from cases of vaginitis and from faeces from the same geographical area. Journal of Clinical Pathology 40: 1159-1161.

Jann K, Jann B 1985 Cell surface components and virulence. Escherichia coli $\mathrm{O}$ and $\mathrm{K}$ antigens in relation to virulence and pathogenicity. In: Sussman M (ed) The virulence of Escherichia coli; reviews and methods. Academic Press, London, pp 157-176.

Lee W, Burnie J, Matthews R 1986 Fingerprinting Candida albicans. Journal of Immunological Methods 93: 177-182.

McCreight M C, Warnock D W 1982 Enhanced differentiation of isolates of Candida albicans using a modified resistogram method. Mykosen 25 : 589-598.

Morse S A, Brooks G F 1985 Neisseria gonorrhoeae taxonomy, colony phenotypes and disease. In: Brooks G F, Donegan E A (eds) Gonococcal infection. Edward Arnold, London, pp 3-8.

Munoz J J, Bergman R K (eds) 1977 The Bordetella pertussis cell and its biological activities in animals. In: Bordetella pertussis. Immunological and other biological activities. Marcel Dekker, New York, pp 13-70.

Odds F C, Abbott A B 1980 A simple system for the presumptive identification of Candida albicans and differentiation of strains within the species. Sabouraudia 18: 301-317.
Odds F C, Abbott A B, Reed T A G, Willmott F E $1983 a$ Candida albicans strain types from the genitalia of patients with and without Candida infection. European Journal of Obstetrics Gynaecology and Reproductive Biology 15: 37-43.

Odds F C, Abbott A B, Stiller R L, Scholer H J, Polak A, Stevens D A $1983 b$ Analysis of Candida albicans phenotypes from different geographical and anatomical sources. Journal of Clinical Microbiology 18: 849-857.

Phongpaichit S, Mackenzie D W R, Fraser C 1987 Strain differentiation of Candida albicans by morphotyping. Epidemiology and Infection 99: 421-428.

Polonelli L, Archibusacci C, Sestito M, Morace G 1983 Killer system : a simple method for differentiating Candida albicans strains. Journal of Clinical Microbiology 17: 774-780.

Roman M C, Linares Sicilia M J 1983 Preliminary investigation of Candida albicans biovars. Journal of Clinical Microbiology 18: 430-431.

Scherer S, Stevens D A 1987 Application of DNA typing methods to epidemiology and taxonomy of Candida species. Journal of Clinical Microbiology 25 : 675-679.

Sereny B 1977 Biological features of enteric bacteria capable of intracellular parasitism. In: Voino-Yasenetsky M V, Bakacs $T$ (eds) Pathogenesis of intestinal infections: microbiological and pathological principles. Akadémiai Kiadó, Budapest, pp 32-40.

Slutsky B, Buffo J, Soll D R 1985 High-frequency switching of colonial morphology in Candida albicans. Science 230: 666 669.

Soll D R, Langtimm C J, McDowell J, Hicks J, Galask R 1987 High-frequency switching in Candida strains isolated from vaginitis patients. Journal of Clinical Microbiology 25: 1611 1622.

Turk D C 1982 Clinical importance of Haemophilus influenzae1981. In: Sell S H, Wright P F (eds) Haemophilus influenzae. Epidemiology immunology and prevention of disease. Elsevier Biomedical, New York, pp 3-9. 